\title{
Experimental Investigation on thermal-hydraulic performance of microchannel heat sink with airfoil pin fin array and supercritical carbon dioxide
}

\author{
Mostafa Asadzadeh $^{(1)}$, Yoav Peles ${ }^{(2)}$ \\ Department of Mechanical and Aerospace Engineering, University of Central Florida \\ P.O. Box 162450 \\ Orlando, FL, USA, 32186-2450 \\ Email: asadzade@knights.ucf.edu
}

\begin{abstract}
Supercritical carbon dioxide $\left(\mathrm{SCO}_{2}\right)$ has shown an excellent capability in cooling applications in recent decade for its stunningly high thermal efficiency along pseudocritical line. Airfoil shaped staggered micro pin fin array were modeled and designed inside the microchannel according to NACA 0030 standard profile with chord span of $160 \mu \mathrm{m}$, height of $100 \mu \mathrm{m}$, and dimensionless longitudinal an traversal pitch ratio of $\zeta_{\mathrm{s}=}$ $2 L_{s} / L_{h}, \zeta_{\mathrm{h}}=2 L_{h} / L_{c}, \zeta_{\mathrm{v}}=2 L_{v} / L_{t}$. Then microfluidic device was fabricated at cleanroom. In this study, preliminary results for heat transfer performance of $\mathrm{SCO}_{2}$ including local and average surface temperature, heat transfer coefficient, Nusselt number as a function of Reynolds number and Prandtl number, and the effect of applied heat flux on pressure drop are presented. In all experiments a pick value for heat transfer coefficient is observed at reduced temperature $\left(\mathrm{T}_{\text {bulk }} / \mathrm{T}_{\mathrm{PC}}\right)$ and pressure $\left(\mathrm{P}_{\text {bulk }} / \mathrm{P}_{\mathrm{PC}}\right)$ near unity. High values of heat transfer coefficient and Nusselt number up to $105000 \mathrm{w} / \mathrm{m}^{2} \mathrm{k}$ and 110 are obtained. Up to $70 \%$ deviation in Nusselt number is observed between experimental data and conventional correlation used in text books for internal turbulent flow, which illustrates the need for developing new correlations for $\mathrm{SCO}_{2}$ with airfoil pin fin heat sink in micro scale. Also, small values of pressure drops up to $0.4 \mathrm{MPa}$ is observed while using airfoil fin array, which is due to very small amount of friction coefficients for airfoil geometries.
\end{abstract}

KEY WORDS: Supercritical Carbon Dioxide, Airfoil-shape Micro Pin Fin Array, Microfluidic Device, Microfabrication, Heat Transfer Performance, Nusselt Number, Pressure Drop

\section{INTRODUCTION}

Supercritical Carbon Dioxide has shown a great potential for a range of industry because of exceptional thermophysical properties at supercritical sate where the fluid is with a gas-like appearance but liquid-like density. It can be used in power generation, stationary and transport refrigeration, heat pump application as well as electronics cooling [1].

$\mathrm{SCO}_{2}$ has been considered as a great working fluid in power plants over past decade. It has been shown that using $\mathrm{SCO}_{2}$ at Bryton cycle can dramatically increase the efficiency of thermodynamic cycle since $\mathrm{SCO}_{2}$ requires much lower compression work due to its higher density than conventional gases. Moreover, as carbon dioxide in its critical state has very low viscosity, pressure drop is significantly decreased. Thus, it can deliver more net power leading to an increase in efficiency. It also can be used in steam turbine for a range of reasons. First, due to lower compression work and pressure drop in the entire system, some components of a power cycle such as a compressor can be down sized, which leads to much smaller size of turbomachinery. For instance, the size of a $20 \mathrm{MW}$ steam turbine can be reduced by a factor of 7 to $14 \mathrm{MW} \mathrm{SCO}_{2}$ turbine. Besides, $\mathrm{SCO}_{2}$ is a single-phase working fluid. Two-phase flow usually introduces corrosion on turbine blades due to existence of liquid drops in the flow. Hence, the maintenance costs of steam turbine operated with single flow, will be astonishingly reduced by using $\mathrm{SCO}_{2}$. Carbon dioxide is also abundant in nature. It is nonreactive with common metals, and other materials, and requires less air flow (in process of cooling) compared to an air-cooled condenser for water[2-3]. There are a lot of zero emission sustainable methods to easily capture it from the environment one of which is solid-state sustainable $\mathrm{CO}_{2}$ collector ( $\mathrm{SCC}$ ), which is activated by solar heat localization [4].

$\mathrm{SCO}_{2}$ can also be used in the refrigeration and heat pump industry. One of the most important issues of refrigerants are their harmful environmental effects. They normally have harmful effects on the ozone layer. Ozone depletion potential (ODP) is a global criterion that shows the corrosion level of refrigerants series such as Chlorofluorocarbons (CFC), Hydrochloro-fluoro-carbons (HCFC) and the Hydrofluorocarbons (HFC). Among all refrigerants carbon dioxide has ODP of zero whereas mentioned refrigerants have ODPs ranging from 0 to 10 [5], [6]. Global Warming Potential (GWP) is another criterion that measures the effect of different refrigerants on global warming. Among all refrigerants carbon dioxide has GWP of 1 while refrigerants have GWPs ranging from 1 to 4800 [7], [8]. Thus, using $\mathrm{SCO}_{2}$ in cooling cycle can play a significant role in carbon footprint reduction to solve greenhouse gases emission. It is also nontoxic, nonflammable, inexpensive component [9]. In contrast, since supercritical state is achievable in relatively high pressures, the cost of components in a $\mathrm{SCO}_{2}$ system is expensive. Considering all these parameters, the cost of cooling system working with $\mathrm{SCO}_{2}$ can approach a cooling systems working with HFCs [10]. Also, it is possible to use liquid like $\mathrm{SCO}_{2}$ in micro and nano cooling system that requires no bubble generation. It has been shown that thin film evaporation of liquid fluids will be bubble free given that the dimension of Nano channels is smaller than critical nucleus dimension [11].

$\mathrm{SCO}_{2}$ may also be use in heat pumps as working fluid. Since it requires less power for compression, it makes a higher volumetric efficiency. Furthermore, the coefficient of performance (COP) of a $\mathrm{SCO}_{2}$-operated heat pump is about 4 times more than that of water-operated heat pumps [12], [13]. Several companies such as Danfoss, Denso and Ecocute are 
working on $\mathrm{SCO}_{2}$-operated heat pumps and air-conditioning systems.

Desired thermophysical properties for heat transfer applications often occurs at supercritical state for an arbitrary cooling fluid. Supercritical state of carbon dioxide corresponds to $31.25^{\circ} \mathrm{C}$ and $7.3 \mathrm{MPa}$. However, the corresponding condition for water is $374{ }^{\circ} \mathrm{C}$ and $21.8 \mathrm{MPa}$. As a result, the thermophysical properties of $\mathrm{SCO}_{2}$ are favorable due to its relatively low critical temperature and pressure [14].

There are few studies on application of scow at microscale. Since micro channels has shown strong potential in heat and mass transfer phenomena [15], application of $\mathrm{SCO}_{2}$ in microchannels are field of interest in present study.

\section{METHODOLOGY}

The goal of this study is to elucidate the thermal performance of microchannel with airfoil micro pin fin arrays in super critical $\mathrm{CO}_{2}$ micro fluidic flow, including heat transfer coefficient, Nusselt number as well as effect of different arrangement of airfoil fins such as inline and staggered in turbulent flow regime. In this regard, the steps through which this study is carried out comprises device design, including modeling of microfluidic device, heater, RTDs, vias and contact pads, stress analysis, uncertainty analysis of electronic components, microfabrication process, package design including main body design for connections, sealing for high pressure, PCB board, and cover plate. These steps will be chronologically explained in the following order.

\section{Device Design}

The device bottom part and top part is made from silicon wafer and brofloat33 glass, respectively. The bottom part is from silicon since silicon is highly thermally conductive, and this make the heat transfer measurements more accurate. In addition, silicon has high yield stress and young modulus enough for microfluidic device to bear high pressure, above critical point of $\mathrm{CO}_{2}$. The top part is made from brofloat 33 glass due to its compatibility with silicon for anodic bonding which is one of the strongest atomic bonding ever known [16][17]. In other word, both materials have alkali components that is crucial for anodic bonding [18]. Another reason to select glass is to visualize the flow during experiment by microscope through a transparent material.

Main features of the device include inlet, outlet, micro channels, and air gaps. For uniform flow distribution in high width to height aspect ratio microchannel, inlet and outlet were designed in rectangular shape. Two air gaps are designed both sides of mini channel to eliminate heat loss from the mini channel wall that results in more accurate data acquisition.

Electronics components are integral part of device design in this study since all heat transfer measurements will be accomplished through them. First, heater that is responsible for heating the fluid flow with constant heat flux boundary condition, is needed. Secondly, resistance temperature detector (RTD) which reads the temperature of the fluid locally by changing its resistance is needed. Another crucial component is vias, which is electrical connection between heater/RTD and contact pads, end part of vias by which probes of PCB board will have access to heater and RTDs to apply voltage and read temperature change through power supplies and data acquisition modules respectively. Vias are made from aluminum since it must have low electrical resistance. Besides, its thickness is several orders of magnitude more than other metal layers. Heater and RTDs are made from platinum and titanium due to their high electrical resistivity. Platinum is the integral part of heater and RTD. Titanium is deposited as adhesion layer between substrate and platinum. Considerations about design and dimensions of microelectronic components will be discussed in uncertainty analysis section. Based on information provided in the uncertainty analysis section the RTDs attributed via are designed as shown in Figure 1. The RTDs dimensions are $15 \mu \mathrm{m}$ wide titanium-platinum strip serpentine-patterned. With this design, the resistance of RTDs is $250 \mathrm{Ohm}$. To heat the flow uniformly, we designed a heater beneath micro channels. Heater is designed to have 27-ohm resistivity. Some design consideration such as safe current limit is also applied to prevent heater burn. The heater dimensions are $2 \mathrm{~mm}$ wide by $17 \mathrm{~mm}$ long titanium-platinum rectangular strip underneath the microchannels. Figure 1 shows the microfabricated RTDs and heater configurations on the silicon substrate.

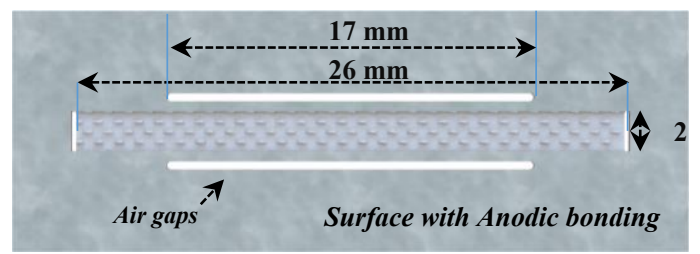

(a)

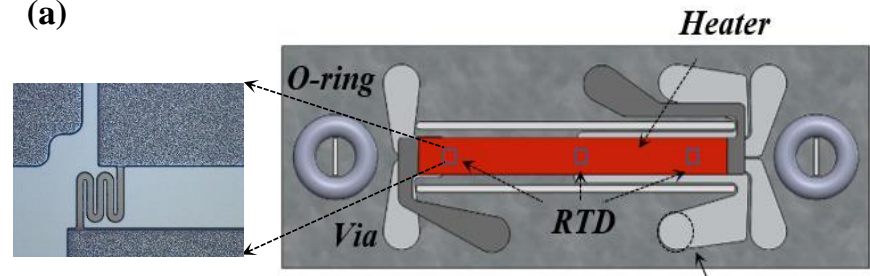

(b)

Contact Pad

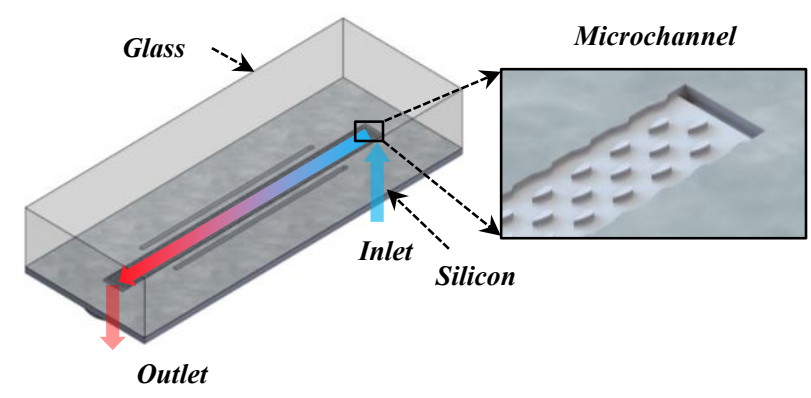

(c)

Fig 1. CAD design of microfluidic device; a) front side including micro channel area for $2 \mathrm{~mm} \times 26 \mathrm{~mm}$, device inlet/outlet for $0.24 \mathrm{~mm} \times 2 \mathrm{~mm}$, air gap for $17 \mathrm{~mm} \times 0.4 \mathrm{~mm}, \mathrm{~b}$ ) electronic side including microelectronic components, c) Completed microfluidic device after dicing

\section{Strength analysis}

Since the microfluidic device is going to work with highpressure fluid flow, it requires some structural analysis to see if the device manage to withstand with high pressure. Hence, a 
comprehensive structural analysis is carried out to determine the thickness of both silicon and glass wafer, allowable micro channel width by which device will tolerate high pressure, and inlet/outlet and airgap dimension. Figure 2 shows the CAD model of the device cross section with fine grids for numerical analysis, and stress distribution in silicon and glass parts respectively.

(a)

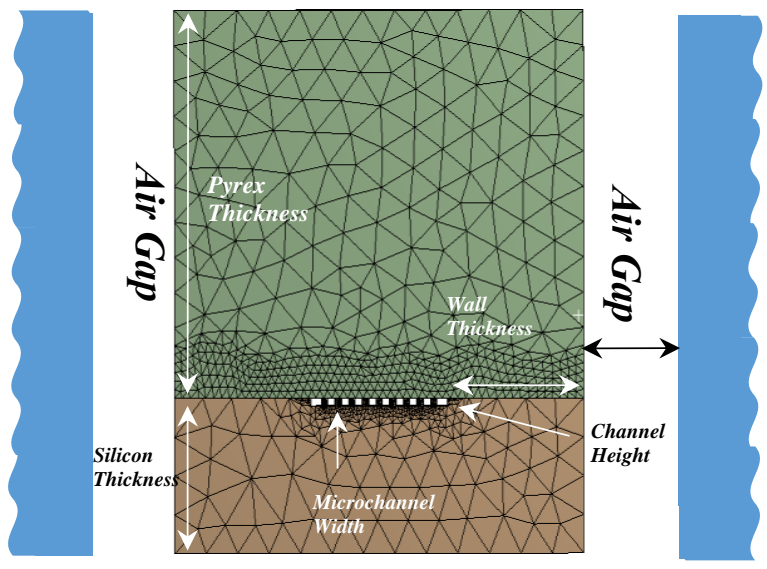

(b)

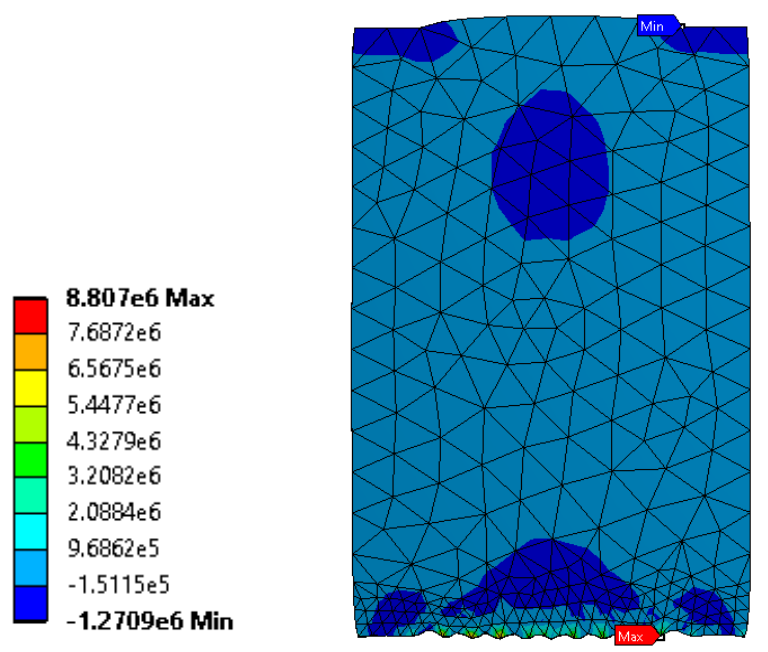

(c)
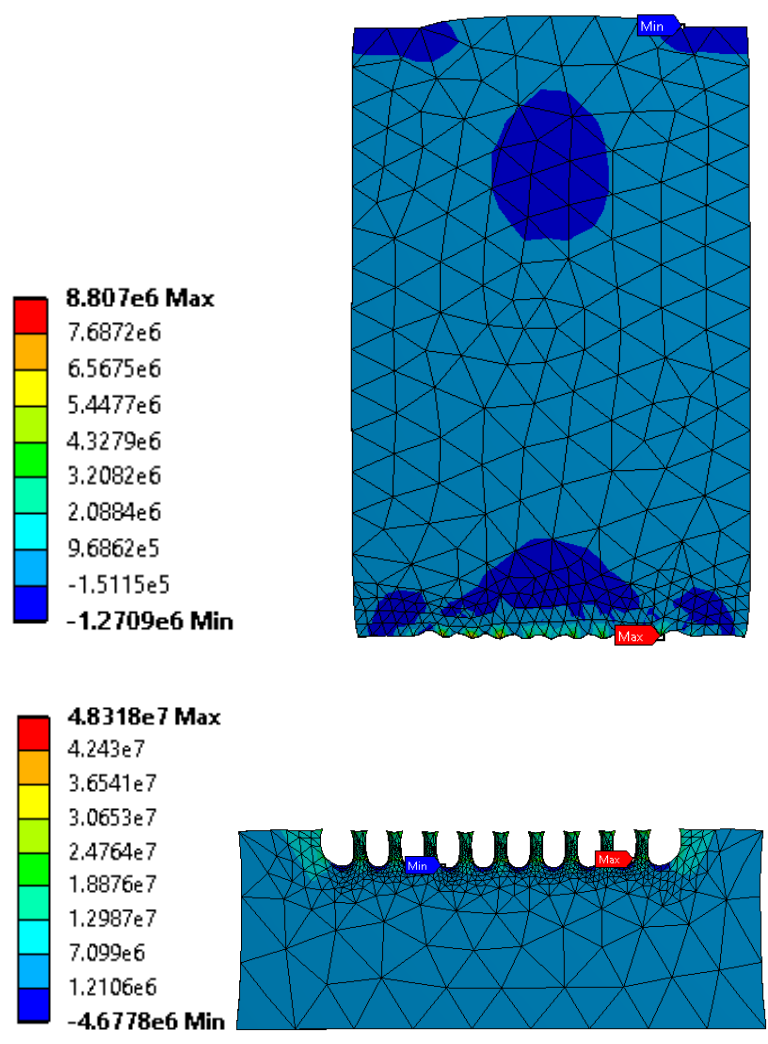

Figure 2. a) Numerical analysis of stress to determine labeled dimensions, airgap width: $1 \mathrm{~mm}$, silicon thickness: $1 \mathrm{~mm}$, Pyrex thickness: $5 \mathrm{~mm}$, micro channels width: $2 \mathrm{~mm}$, micro channel height: $100 \mu \mathrm{m}$, wall thickness: $100 \mu \mathrm{m}, \mathrm{b})$ Maximum principal stress for silicon substrate, c) Maximum principal stress for glass part.

As shown in Figure 2, different values for silicon and glass thickness, wall thickness (silicon thickness between mini channel wall and air gap), micro channel height and width were obtained in numerical analysis. The software used was Ansys 2017 student version [19]. Since there was number of grid limitation for this version up to 20000 grids, the grid study was done for 13000, 16000 and 20000 as coarse, medium and fine mesh grids to verify the numerical simulations. Finally, the silicon part dimensions of $12 \times 32 \times 1 \mathrm{~mm}$ in width, length and height, the glass part dimensions of $12 \times 32 \times 5 \mathrm{~mm}$ was selected. Wall thickness between side channel and air gap for $0.1 \mathrm{~mm}$. micro channel width and height of 50 and $100 \mu \mathrm{m}$, and aspect ratio of $\mathrm{L} / \mathrm{D}=2$ were designed. Knowing these optimum values for dimensions, maximum principal stress in silicon and glass parts are $48.43 \mathrm{MPa}$ and $8.8 \mathrm{MPa}$, and the yield stress of the two components are 214 and $25 \mathrm{MPa}$ respectively. Hence, there is safety factors of 5 and 2.8 in this design for the two materials. The critical stress will happen at microchannel-wall interface and bonding location in silicon and glass parts respectively. As we can see, the glass part is more in danger of failure than silicon due to having an opening on top of glass for visualization of phenomena. This opening must be as wide as mini channel width.

\section{Uncertainty analysis}

For RTD-vias coupling design the uncertainty analysis must be done, meaning to make sure that measurement error due to metals electrical resistivity dependence on temperature is not remarkable for the case of error considerations. Equation (1) shows relation of resistivity of platinum, titanium and aluminum to temperature

$$
\begin{aligned}
& \rho(T)=\rho_{0}\left[1+\alpha\left(T-T_{0}\right)\right] \\
& R=\frac{\rho L}{A}
\end{aligned}
$$

Where $\alpha$ is the temperature coefficient of resistivity, $T_{0}$ is a fixed reference temperature (usually room temperature), and $\rho_{0}$ is the resistivity at temperature $T_{0}$. Parameter $\alpha$ is an empirical parameter fitted from measurement data. Because the linear approximation is only an approximation, $\alpha$ is different for different reference temperatures [20]. The $\alpha$ is a thermophysical properties of material. Normally this value for aluminum is an order of magnetite lower than that of platinum. That is why aluminum is usually used for via fabrication. In general, equation (2) should be considered between selected metals.

$$
\frac{R_{v i a}}{R_{R T D}} \leq 1 \%
$$

Which means the electrical resistance of via should be two order of magnitude less than that of RTDs. Considering the temperature $20^{\circ} \mathrm{C}$ as $T_{0}$ and assuming change of flow temperature is from 20 to $50^{\circ} \mathrm{C}$, we will have $0.1^{\circ} \mathrm{C}$ of temperature change in vias $\left(\Delta R_{V i a}\right), 58.36^{\circ} \mathrm{C}$ of temperature change in RTDs $\left(\Delta R_{R T D}\right)$. Hence, the ratio of the total resistance change to the temperature change is:

$$
\frac{\Delta R}{\Delta T}=\frac{\Delta R_{V i a}}{\Delta T}+\frac{\Delta R_{R T D}}{\Delta T}
$$

Therefore, the temperature uncertainty would be:

$$
\Delta R_{\text {Total }}=\Delta R_{R T D}+\Delta R_{\text {Vias }}
$$


$R_{\text {Calibration }}=R_{R T D}(T)+R_{V i a}(T)$

$$
\begin{aligned}
& R_{\text {Real }}=R_{R T D}(T)+R_{\text {Vias }}\left(\frac{20+T}{2}\right) \\
& U\left({ }^{\circ} \mathrm{C}\right)=\left|R_{\text {Real }}-R_{\text {Calibration }}\right| \times \frac{\Delta T}{\Delta R_{\text {Total }}}
\end{aligned}
$$

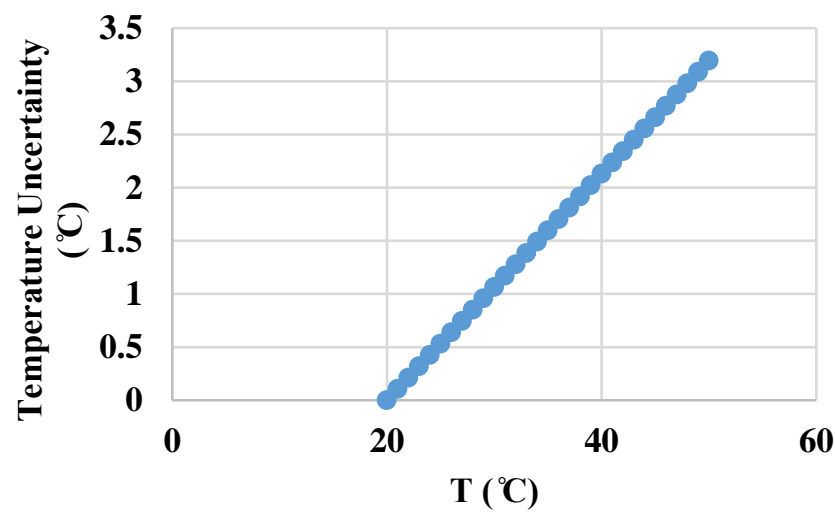

Fig 3. Temperature uncertainty values as a function of temperature in which experiments are carried out

Figure 3 shows the uncertainty change for desired range of temperature. The uncertainty values for the range of temperature during experiment would be less than $3^{\circ} \mathrm{C}$ as shown in Figure 3. Thus, the experimental error due to temperature difference would be negligible for designed RTD and vias configuration.

\section{Microfabrication Process}

Once device design is complete, it is time to develop recipe for micro fabrication process and to make device at clean room. First, bare silicon wafer is cleaned out of organics residues. Then, a $1 \mu \mathrm{m}$ thin layer of silicon oxide was deposited over both sides of the wafer. Afterward, $10 \mathrm{~nm}, 60 \mathrm{~nm}$, and $1 \mu \mathrm{m}$ thin layers of titanium, platinum and aluminum were sputtered over one side of the silicon. Then, the wafer was undergone photolithography processes consisted of soft bake, spin of prime adhesion promoter, spin of photoresist s1818, soft bake, UV exposure and development, respectively. After photolithography process the wafer is undergone wet etch process to form vias of RTDs. Next step is to form RTDs itself. After doing photolithography process by using relevant mask, the wafer is undergone ion reactive etch which is a type of dry etch process. A layer of $\mathrm{SiO}_{2}$ is deposited over the electronic side as an insulator between RTD and heater layer. Until now, the RTDs and relevant visa are micro fabricated. Next step is to repeat all these processes again with the appropriate designed mask to micro fabricate heater layers. Once accomplished, using two masks designed for contact pad removal the assigned region over vias are opened by eliminating the $\mathrm{SiO}_{2}$ layer so that electronic component can connect to power supplies for applying voltage and reading the temperature change during experiment. Next step is deep reactive ion etching process to make the features such as microchannel, inlet, outlet, air gaps on the bonding side. In this regard, a different recipe for photolithography are carried out. Since there is need for a deep silicon etching about $1000 \mu \mathrm{m}$, a combination of soft mask and hard mask are needed. First photolithography process was done by photoresists series SPR and AZ P7904, which provides the surface with a thick layer of photoresist. Then, instead of soft bake using hot plate, the wafer was put into convection oven for a long time. In addition, after exposure the wafers was left for about an hour. The DRIE machine selectivity for photoresist to silicon was 111:1 and for $\mathrm{SiO}_{2}$ to silicon was 401:1. After 900$\mu \mathrm{m}$ deep etching using thick layer of photoresist, it was wiped out by quenching the wafer into photoresist stripper overnight. Afterwards, $100-\mu \mathrm{m}$ DRIE was applied to create the micro channels as well as the inlet outlet and air gaps all the way through the wafer. Then, $\mathrm{SiO}_{2}$ remnants were stripped from the bonding side leaving the original polished silicon surface with the micro channels and other feature. Next step is to clean this surface out of any organic contamination using Surface Clean 1 and 2 recipes, known as acid clean and base clean with ammonium hydroxide and hydrogen peroxide, hydrogen chloride, and DI water. Finally, we used Mega sonic DI water surface polarization. Once cleaning recipe is performed for both broafloate33 glass and the prepared wafer, they were sandwiched right away and were put into bonding machine to apply anodic bonding under $400{ }^{\circ} \mathrm{C}$ and $800-1000$ volts for 10 minutes. Finally, the prepared wafer was gone under dicing process to make each individual device ready for experiments.

Figure 4 shows the prepared electronic side of a sampled wafer, micro channel and airfoil fin arrays.

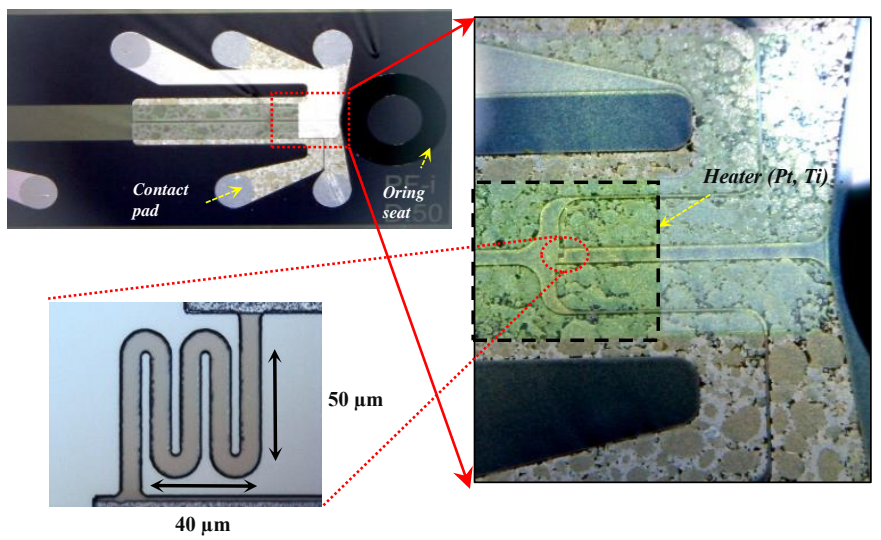

(a)

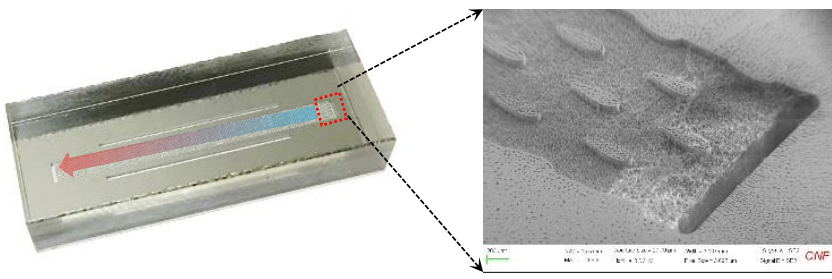

(b)

(c)

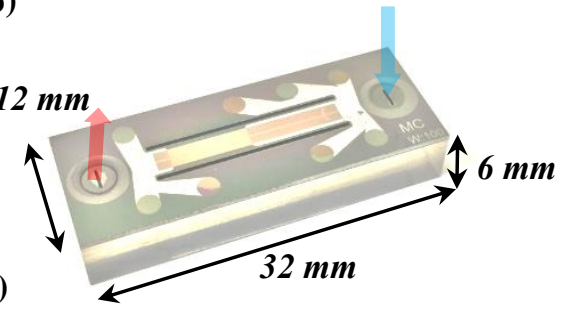

Fig 4. a) Electronic components fabricated over silicon substrate, b) Microfluidic device, and embedded staggered airfoil arrangement heat sink based on NACA0030, c) Dimensions of microfluidic device, inlet and outlet. 
NACA 0030 airfoil geometry is selected as pin fin inside microchannel. This is a symmetric airfoil where the ' 00 ' means it has no camber and the ' 30 ' means the airfoil has a $30 \%$ thickness to the chord length ratio. The SEM image of this airfoil micro pin fin is shown as Figure 5. Channel depth and width are $100 \mu \mathrm{m}$ and $2 \mathrm{~mm}$, respectively. Geometric parameters of the airfoil fin arrangement are shown in Figure 5. The chord length $\mathrm{L}_{\mathrm{c}}$ is $480 \mu \mathrm{m}$ and hence the airfoil thickness $\mathrm{L}_{\mathrm{t}}$ is $160 \mu \mathrm{m} . \mathrm{L}_{\mathrm{s}}, \mathrm{L}_{\mathrm{h}}$ and $\mathrm{Lv}$ indicate staggered pitch, horizontal pitch and vertical pitch, respectively. The geometric dimensionless numbers are defined as below:

$$
\zeta_{\mathrm{s}}=\frac{2 L_{s}}{L_{h}}, \zeta_{\mathrm{h}}=\frac{2 L_{h}}{L_{c}}, \zeta_{\mathrm{v}}=\frac{2 L_{v}}{L_{t}}
$$

According to a research by Kim et al [21], $\zeta_{\mathrm{s}}=1$ has the best performance when both heat transfer and pressure drop are considered, and there is no optimal point for $\zeta_{\mathrm{h}}$ and $\zeta_{\mathrm{v}}$. In the present study, $\zeta_{\mathrm{s}}, \zeta_{\mathrm{h}}$ and $\zeta_{\mathrm{v}}$ are determined as 1,2 and 3.5. Accordingly, $\mathrm{L}_{\mathrm{s}}, \mathrm{L}_{\mathrm{h}}$ and $\mathrm{L}_{\mathrm{v}}$ are $480 \mu \mathrm{m}, 960 \mu \mathrm{m}$, and $560 \mu \mathrm{m}$, respectively. the geometric dimensions in inline micro pin fin arrangement are the same as sttagerred array, except for $\zeta_{\mathrm{s}}$ which is obviously zero.

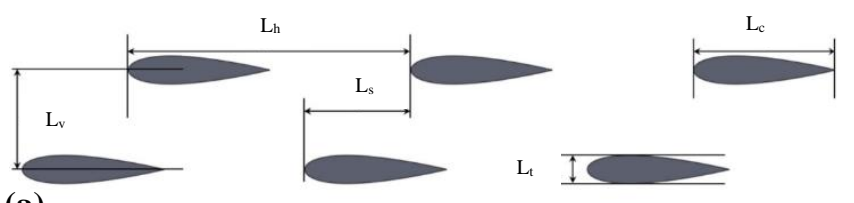

(a)
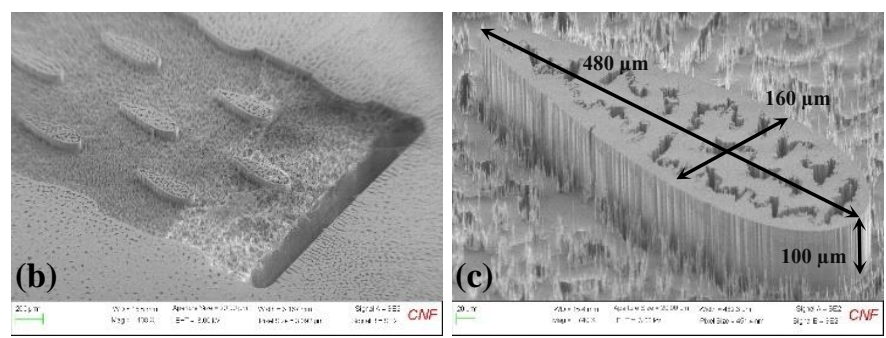

Fig 5. a) Geometric arrangement of micro pin fin arrays inside micro channel. b) SEM image of staggered arrangement. c) SEM image of single airfoil micro fin

Figure 6 shows the inlet, outlet, airgaps and side walls. The side wall effects were tried to be minimized by including half airfoil into the side walls in appropriate positions. The aspect ratio of microchannel width to height is $20: 1$. Inlet and outlet were designed in rectangular shape so that the flow could disperse uniformly between all fins across the channel. The airgap is etched all the through the silicon substrate to minimize the heat loss in transversal direction.
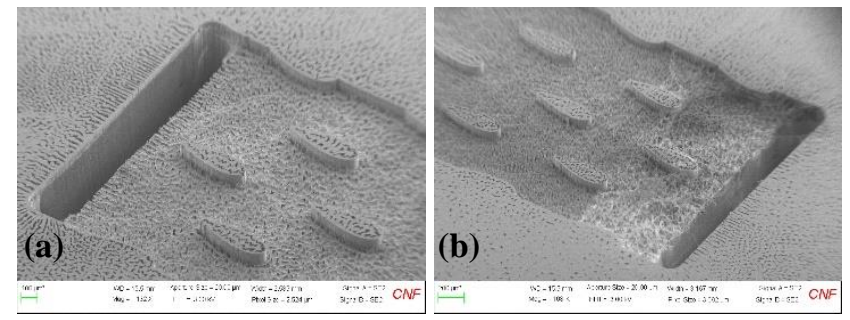
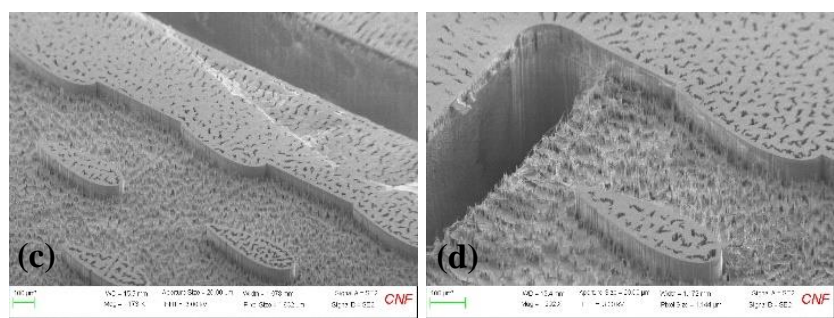

Fig 6. a) rectangular inlet toward which the leading edge of the airfoils are placed. b) rectangular outlet toward which the trailing edge of the airfoils are placed. c) air gaps which is place 400 away from side wall. d) side wall including half airfoil.

\section{Package and Assembly}

To run experiment a suitable package was designed. In this regard, package main body strength and hardness, sealing issues, connections, cover plate and PCB board was considered. To some extent, the package must support the device in a way that it can tolerate high pressure from 7.5 MPa to more than 100 $\mathrm{MPa}$ at connection ports as well as inlet/outlet O-ring glands. Also, its surface hardness should be less than that of device so that the device will not be scratched by the package. With these in mind, the package main body is made from stainless steel $316 \mathrm{~L}$ whose strength is so high and well suited for this application, and its hardness is 3 (in Mohs standards) whereas $\mathrm{SiO}_{2}$ hardness is 7. Another important issue in package design is axial sealing. The O-ring was ordered from Apple Rubber Inc. and the relevant guideline from this company was used to determine dimensions of the O-ring glands in the package [22]. Figure 7 shows a complete package design with fluid flow cross section view.
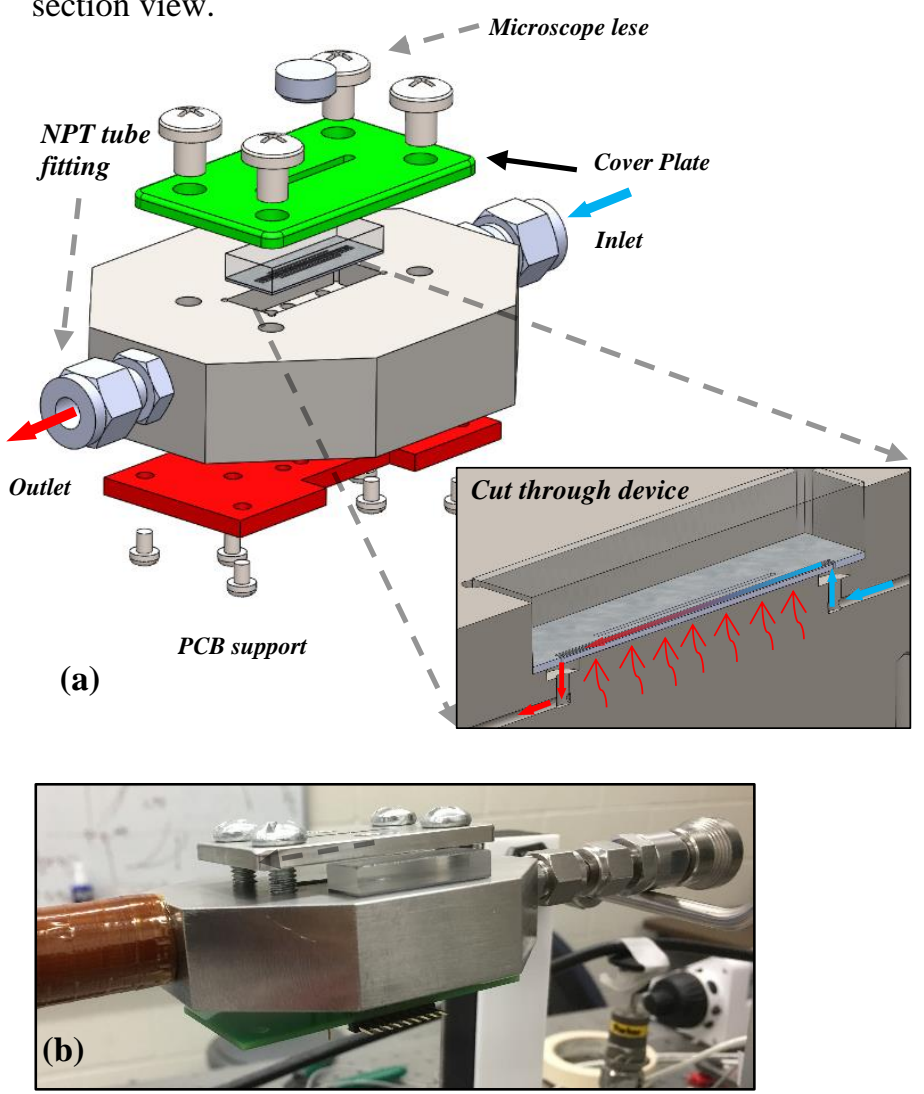

Fig 7. a) Completed package design with details to show how it works, b) Manufactured package and PCB board 


\section{EXPERIMENTAL SET UP}

The experimental set up design was complex because tests carries out with combination of high pressure and low flow rate. That is, the working pressure is between 220 to $5000 \mathrm{psi}$, flow rate is between 1 to 20 SLPM (Standard Liter Per Minute). Two approaches for the test bench are considered as open and closed loop. In closed loop experimental set up the working fluid is available for long-term experiment despite open loop set up in which the working fluid is vented out of enclosed loop and the gas source will be empty after a short time. On the other hand, a pump is needed in closed loop to circulate the flow. Due to low viscosity of $\mathrm{SCO}_{2}$ and low flow rate and high pressure drop inside the loop, there is no appropriate micro pump at the rates and to compensate a large pressure drop. Therefore, positive displacement pump type should have been used which adds instabilities to the working fluid. To solve this problem, the loop needs an accumulator. Also, we need to make sure that inlet flow into the pump will be absolute liquid. Due to a large pressure drop inside the microfluidic device a compressor is needed to make sure that the pump inlet is pure liquid. In contrast, the main components in the open loop experimental set up are only a 6000 psi hydrogen tank, 800 psi $\mathrm{CO}_{2}$ tank, which is needed in closed loop as well, and a pressure vessel to pressurize the carbon dioxide. Thus, price of open loop setup is much less than that of closed loop. In addition, due to existence of compressor in closed loop set up, a lot of noise will be made during experiment. In open loop experimental set up the carbon dioxide gas is vented to the atmosphere at the end of the test set up and approximately after 30 minutes, the $\mathrm{CO}_{2}$ cylinder will be empty out of the liquid phase. Moreover, since the gas is vented to the laboratory atmosphere, safety issues need to be carefully considered. However, this type of test bench decreases the number of components in the experimental set up, reduces the noise of experimental set up. It is also more simple and cheaper. Finally, open loop experimental set up was designed. Figure 8 shows the experimental design for this study. The experimental set up consists of the components such as two pressure cylinders of $860 \mathrm{psi} \mathrm{CO} 2$ for experiment and $5000 \mathrm{psi}$ $\mathrm{N} 2$ for compressing the working fluid which are connected to pressure vessel ordered from HIP Inc shown in Figure 9-d. Ttype thermocouples and model PX-309-5KG5V pressure transducers from OMEGA Inc enabled us to measure inlet and outlet temperature and pressure.

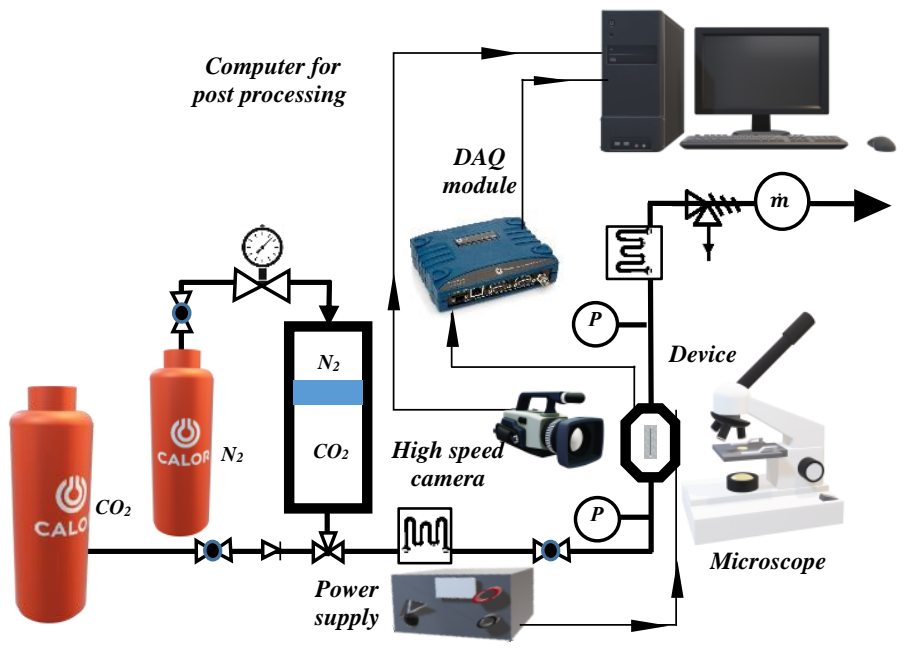

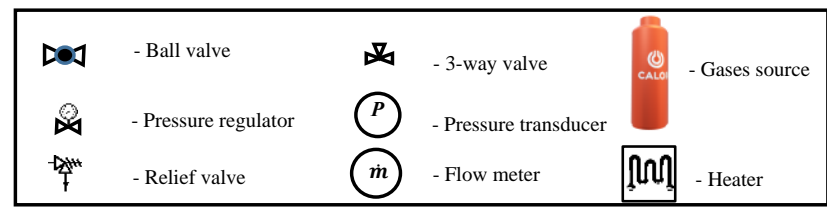

Fig 8. Experimental set up of open loop for heat transfer measurements

Data acquisition systems is bought from National Instrument Company that is capable of being connected to the LabVIEW. NI-9213 C series temperature input module was used to collect temperature data from thermocouples. NI-9205 C SERIES voltage input module was used to gain voltage output data from pressure transducers shown in Figure 9-b. SCXI-1581 analog output module is used for $100 \mu \mathrm{A}$ fixed-current excitation of RTDs. Also, SCXI-1102 voltage input module is linked to SCXI-1581 for reading the induced voltage from RTDs. The two DAQ modulus was mounted on a SCXI 1000 chassis. Microfluidic device is connected to the DAQ devices through the DB37 Dual Breakout Board and CA 143 cable as shown in Figure 9-a. A Keysight power supply was used to create power with a Pt heater which is microfabricated into the microfluidic device and two Agilent multimeters were used to measure current and voltage of the heater for heater heat flux and resistance calculations shown in Figure 9.

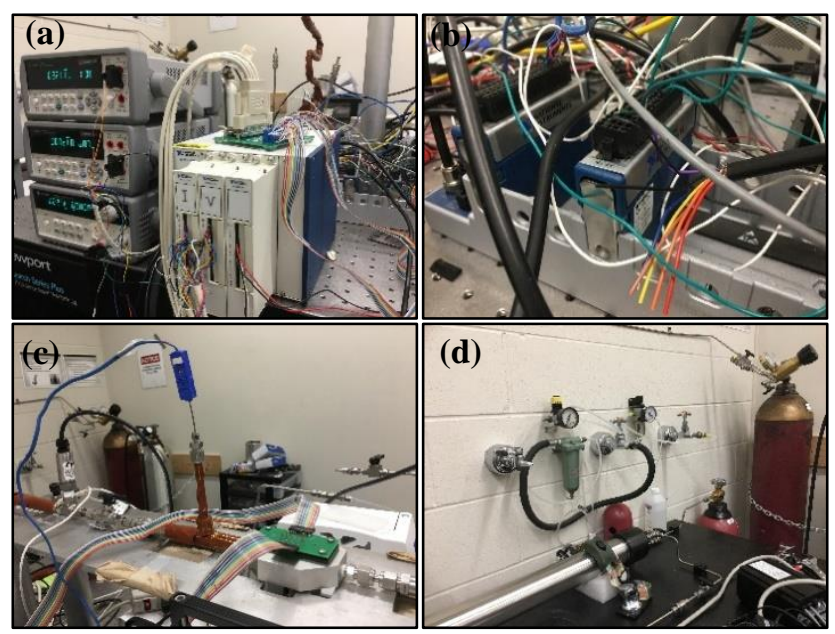

Fig 9. Experimental set up: a) SCXI DAQ systems (rightdown), Keysight power supply and Agilent multimeters for current and voltage measurement (left-bottom to top), and breakout board (top of DAQ). b) NI-9205 (right) and NI-9213 (left) C SERIES voltage and temperature input module. c) Device with the package and PCB board which is connected to the break out board through rainbows. d) Pressure vessel connected to low pressure co2 (short) and ultra-high pressure N2 (tall) cylinders

\section{RESULTS}

\section{Results and Discussion}

As mentioned earlier, goal of this study is to investigate the potential of $\mathrm{SCO}_{2}$ as coolant in micro scale. The result shown in this study is for microchannel device with airfoil fins in staggered arrangement. Figure 10 shows values of pressure drop caused by airfoil pin fin arrangement which is up to 0.4 $\mathrm{MPa}$. The inlet pressure, temperature and mass flux were set to of $8.06 \mathrm{Mpa}, 31.6^{\circ} \mathrm{C}$, and $2500 \mathrm{~kg} / \mathrm{s} . \mathrm{m}^{2}$, respectively. This 
relatively low values of pressure drop is due to highly low friction coefficient that could be obtained by specific shape of airfoil geometry which is lower than any other geometries. As applied heat flux increases, the pressure drop increases.

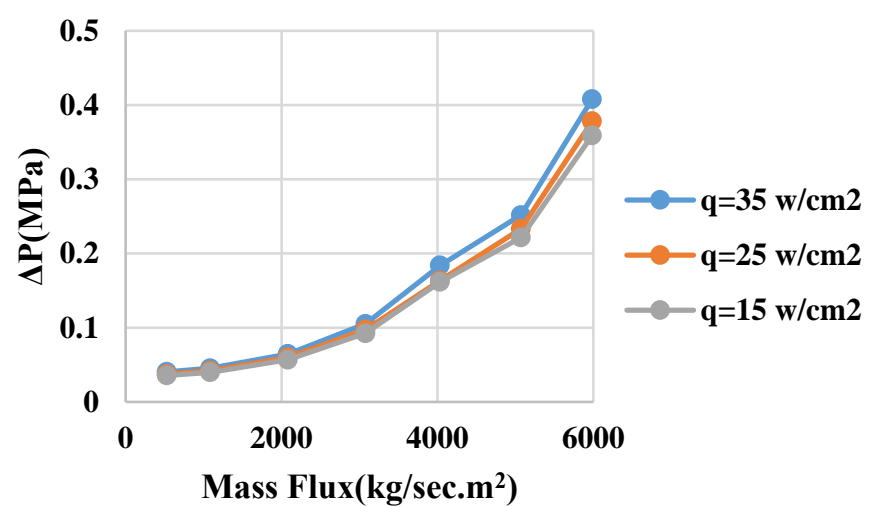

Fig 10. Pressure drop versus mass fluxes for different heat fluxes

Another important result observed was the temperature change of the heater surface for different heat fluxes measured by resistance temperature detectors (RTDs). Firstly, RTDs are calibrated inside the lab oven. Then, using calibration curve and the values of resistance shown in Labview, the local surface temperature of the microchannel can be measured. The heater resistance was also used to measure the average surface temperature of the micro channel.

Figure 11 shows the temperature difference of each RTD and heater with respect to the inlet temperature versus applied heat flux. As shown in this figure, the surface temperature of the heater linearly increases as heat flux increases.

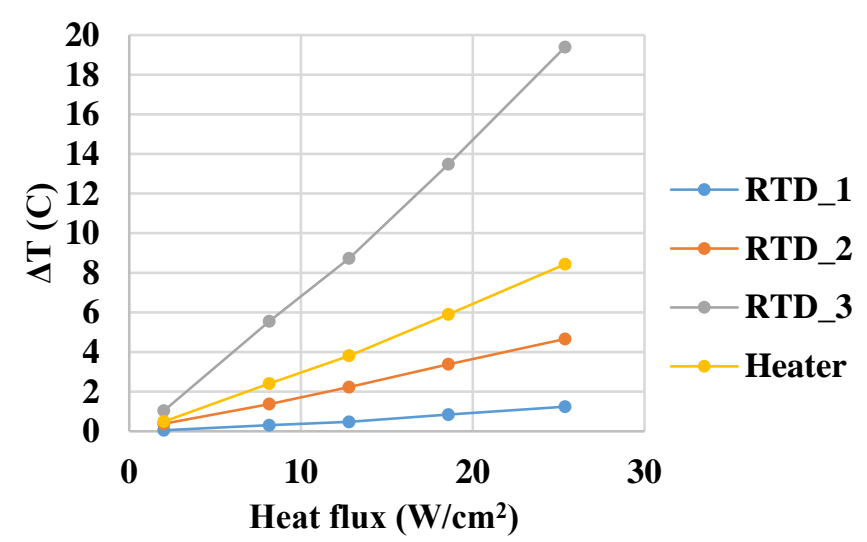

Fig 11. Local and average surface temperature changes relative to ambient temperature for different values of heat flux.

To calculate HTC newtons's law of heat transfer requires the fluid temperature.

$$
H T C=\frac{Q}{A\left(T_{s}-T_{f}\right)}
$$

Where $T_{S}$ is the surface temperature that is measured by RTDs, $T_{f}$ is the fluid bulk temperature, $Q$ is the amount of power generated by the heater, and $A$ is the heated surface area.
Applying the first law of thermodynamic for the microchannel as control volume, we have:

$$
Q=\dot{m} C_{p}\left(T_{\text {out }}-T_{\text {in }}\right)
$$

Where $T_{i n}$ is the inlet temperature that is measured by the thermocouple mounted in the experimental set up, $C_{p}$ is the specific heat of $\mathrm{CO}_{2}$ which is taken from REFPROP data set [23], $Q$ is the net heat that is directly transferred from the heater to the flow, and $\dot{m}$ is the mass flow rate inside the micro channel, measure by flow meter. The only unknown value is $T_{\text {out }}$. By discretizing the flow field into 200 unit cells and developing Matlab code we calculated $T_{\text {out }}$ in each cell by means of data obtained from the previous cell to capture the average fluid temperature profile along the micro channel. The average values between inlet and outlet temperature in each cell was assumed to be the bulk fluid temperature.

$$
T_{f}=\frac{T_{\text {in }}+T_{\text {out }}}{2}
$$

Knowing $T_{f}$ convective heat transfer coefficient was calculated from Eq 6. Figure 12-a shows the result of heat transfer coefficient for different values of heat flux applied to the fluid flow.
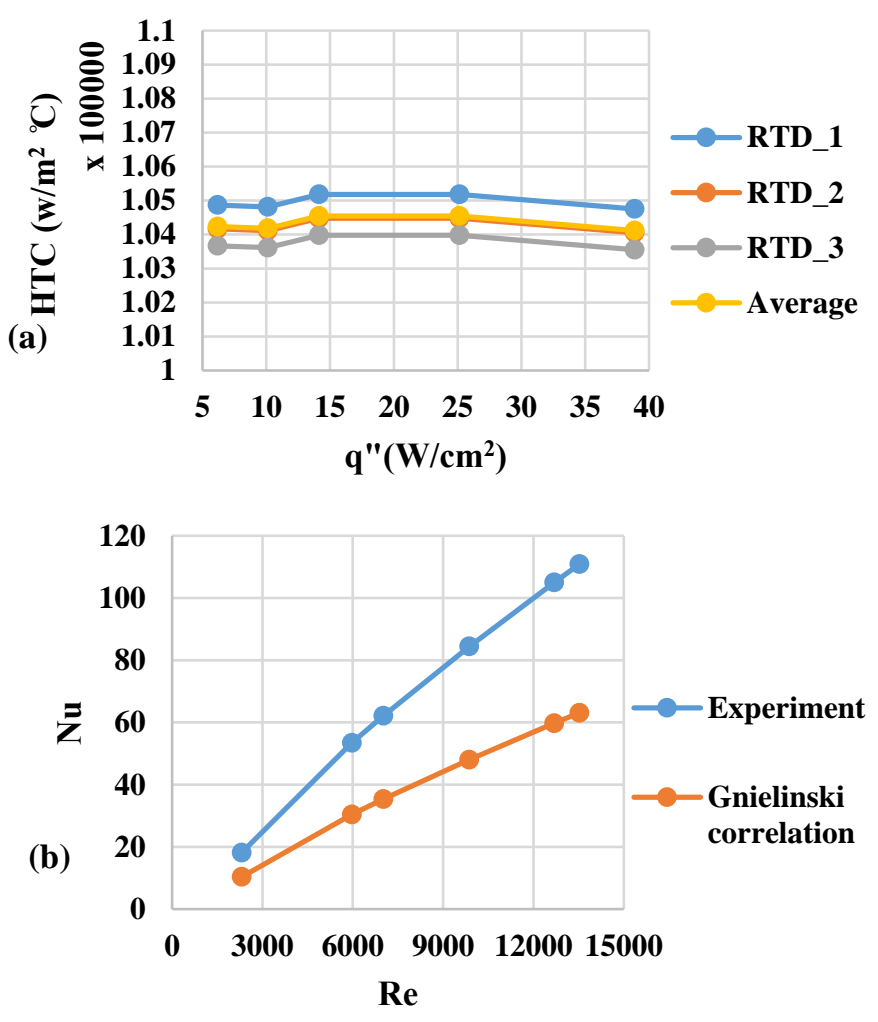

Fig 12. a) Convective heat transfer coefficient as a function of heat flux, b) Nusselt number as a function of Reynolds number and Prandtl number

As shown in Figure 12-a, the obtained HTC is up to 92000 $\mathrm{w} / \mathrm{m}^{2} \mathrm{k}$ which is astonishingly high number compared to other refrigerants studied in literature. Also, it is independent from the heat flux applied to the microchannel. Figure 12-b illustrates the amount of Nusselt number as a function of Reynolds number while the Prandtl number is 2 . The experimental results 
is compared to the Gnielinski [24] correlation for internal turbulent flow. The correlation deviates up to $70 \%$ from experimental result of $\mathrm{SCO}_{2}$ in staggered airfoil fin heat sink, which shows the importance of developing new correlations for supercritical $\mathrm{CO}_{2}$ in microscale.

\section{SUMMARY \& CONCLUSIONS}

$\mathrm{SCO}_{2}$ has been under research to examine its potential in various field of energy conversion including power generation, stationary and transport refrigeration. In this study, thermalhydraulic performance of supercritical carbon dioxide was examined in microchannels with staggered NACA 0030 airfoil fin arrangement. High values of heat transfer coefficient were achieved with carbon dioxide as coolant at microscale in a range of temperature closer to ambient. It is concluded that $\mathrm{CO}_{2}$ near supercritical state can increase thermal performance of the microfluidic system. Also, the amount of pressure drop was drastically reduced by 40 percent relative to the microchannel with Square pin fin array. That is, airfoil fin array not only helps the microfluidic device to increase the thermal performance, but also plays a key role on reducing pressure drop of the system, meaning increasing the hydraulic performance of the device. For future study, effect of different types of airfoil NACA00 series on thermal-hydraulic performance of microfluidic device will be studied.

\section{ACKNOWLEDGMENTS}

The authors would like to thank all collaboration institutions. Office of Naval Research (ONR) supports this research. Also, the microfabrication process is accomplished in Cornell Nanoscience \& Technology Facility (CNF) at Cornell university. We also thank Dr. Subith Vasu and Dr. Jayanta Kapat, faculty members of department of mechanical and aerospace engineering at University of Central Florida, for their valuable instructions.

\section{REFERENCES}

[1] A. S. Danfoss, "Save energy and protect the environment with $\mathrm{CO} 2$ solutions, Commercial and Industrial Refrigeration," pp. PP4-5, 2015.

[2] A. P. Technologies et al., "Supercritical Carbon Dioxide Brayton Cycle," 2015.

[3] Y. Ahn et al., "Review of supercritical CO2power cycle technology and current status of research and development," Nucl. Eng. Technol., vol. 47, no. 6, pp. 647-661, 2015.

[4] V. Kashyap et al., "Capture and conversion of carbon dioxide by solar heat localization," Sustain. Energy Fuels, vol. 3, no. 1, pp. 272-279, Dec. 2019.

[5] "CO2 As Refrigerant: The Transcritical Cycle." [Online]. Available:

https://www.achrnews.com/articles/94092-co2-asrefrigerant-the-transcritical-cycle. [Accessed: 14-Jan2019].

[6] J. T. McMullan, "Refrigeration and the environment - issues and strategies for the future," Int. J. Refrig., vol. 25, no. 1, pp. 89-99, Jan. 2002.

[7] B. A. Fricke, V. Sharma, and O. Abdelaziz, "Low Global Warming Potential Refrigerants for
Commercial Refrigeration Systems," 2017.

[8] M. O. McLinden, J. S. Brown, R. Brignoli, A. F. Kazakov, and P. A. Domanski, "Limited options for low-global-warming-potential refrigerants," Nat. Commun., vol. 8, p. 14476, Feb. 2017.

[9] B. O. Bolaji and Z. Huan, "Ozone depletion and global warming: Case for the use of natural refrigerant - a review," Renew. Sustain. Energy Rev., vol. 18, pp. 49-54, Feb. 2013.

[10] A. Pearson, "Carbon dioxide - New uses for an old refrigerant," Int. J. Refrig., vol. 28, no. 8, pp. 11401148, 2005.

[11] M. Nazari, A. Masoudi, P. Jafari, P. Irajizad, V. Kashyap, and H. Ghasemi, "Ultrahigh Evaporative Heat Fluxes in Nanoconfined Geometries," Langmuir, vol. 35, no. 1, pp. 78-85, Jan. 2019.

[12] B. T. Austin and K. Sumathy, "Transcritical carbon dioxide heat pump systems: A review," Renew. Sustain. Energy Rev., vol. 15, pp. 4013-4029, 2011.

[13] "Commercial CO2 Refrigeration Systems, Guide for Subcritical and Transcritical CO2 Applications." Emerson Climate Technologies, Inc., 2015.

[14] I. Pioro and S. Mokry, "Thermophysical Properties at Critical and Supercritical Pressures," Heat Transf. Theor. Anal. Exp. Investig. Ind. Syst., 2011.

[15] M. Asadzade and A. Shamloo, "Design and simulation of a novel bipolar plate based on lung-shaped bioinspired flow pattern for PEM fuel cell," Int. J. Energy Res., vol. 41, no. 12, 2017.

[16] T. Rogers and J. Kowal, "Selection of glass, anodic bonding conditions and material compatibility for silicon-glass capacitive sensors," Sensors Actuators A Phys., vol. 46, no. 1-3, pp. 113-120, Jan. 1995.

[17] D. E. Carlson, K. W. Hang, and G. F. Stockdale, "Electrode 'Polarization' in Alkali-Containing Glasses," J. Am. Ceram. Soc., vol. 55, no. 7, pp. 337341, Jul. 1972.

[18] A. C. Lapadatu and H. Jakobsen, "Anodic Bonding," Handb. Silicon Based MEMS Mater. Technol., pp. 599-610, Jan. 2015.

[19] “ANSYS, Inc. Release Notes,” 2016.

[20] R. A. Matula, "Electrical resistivity of copper, gold, palladium, and silver," J. Phys. Chem. Ref. Data, vol. 8, no. 4, pp. 1147-1298, Oct. 1979.

[21] T. H. Kim, J. G. Kwon, S. H. Yoon, H. S. Park, M. H. Kim, and J. E. Cha, "Numerical analysis of air-foil shaped fin performance in printed circuit heat exchanger in a supercritical carbon dioxide power cycle," Nucl. Eng. Des., vol. 288, pp. 110-118, Jul. 2015.

[22] "Seal Design Guide, APPLE RUBBER Products, pp18-19, 2018."

[23] "NIST Reference Fluid Thermodynamic and Transport Properties Database (REFPROP), Version 10."

[24] V. Gnielinski, "New equations for heat and mass transfer in turbulent pipe and channel flow," Int. J. Chem. Eng., vol. 16, pp. 359-368, 1976. 